\title{
Nadrian C. Seeman (1945-2021): pioneer of DNA nanotechnology
}

\author{
Istvan Hargittai ${ }^{1} \cdot$ Balazs Hargittai $^{2}$
}

Published online: 1 March 2022

(c) The Author(s), under exclusive licence to Springer Science+Business Media, LLC, part of Springer Nature 2022

\begin{abstract}
Nadrian (Ned) Seeman (1945-2021) was a crystallographer turned nanoscientist who pioneered a new direction of research at the borderline of the two fields. He constructed new structures and new devices from DNA molecules and opened up new vistas in pursuing and applying innovations in the science of structures.
\end{abstract}

Keywords Nadrian C. Seeman · DNA nanotechnology $\cdot$ Holliday junction $\cdot$ Nanoscale control $\cdot$ Kavli Prize

Fig. 1 Ned Seeman in his laboratory with DNA models, 1995, at New York University. Photograph by the authors

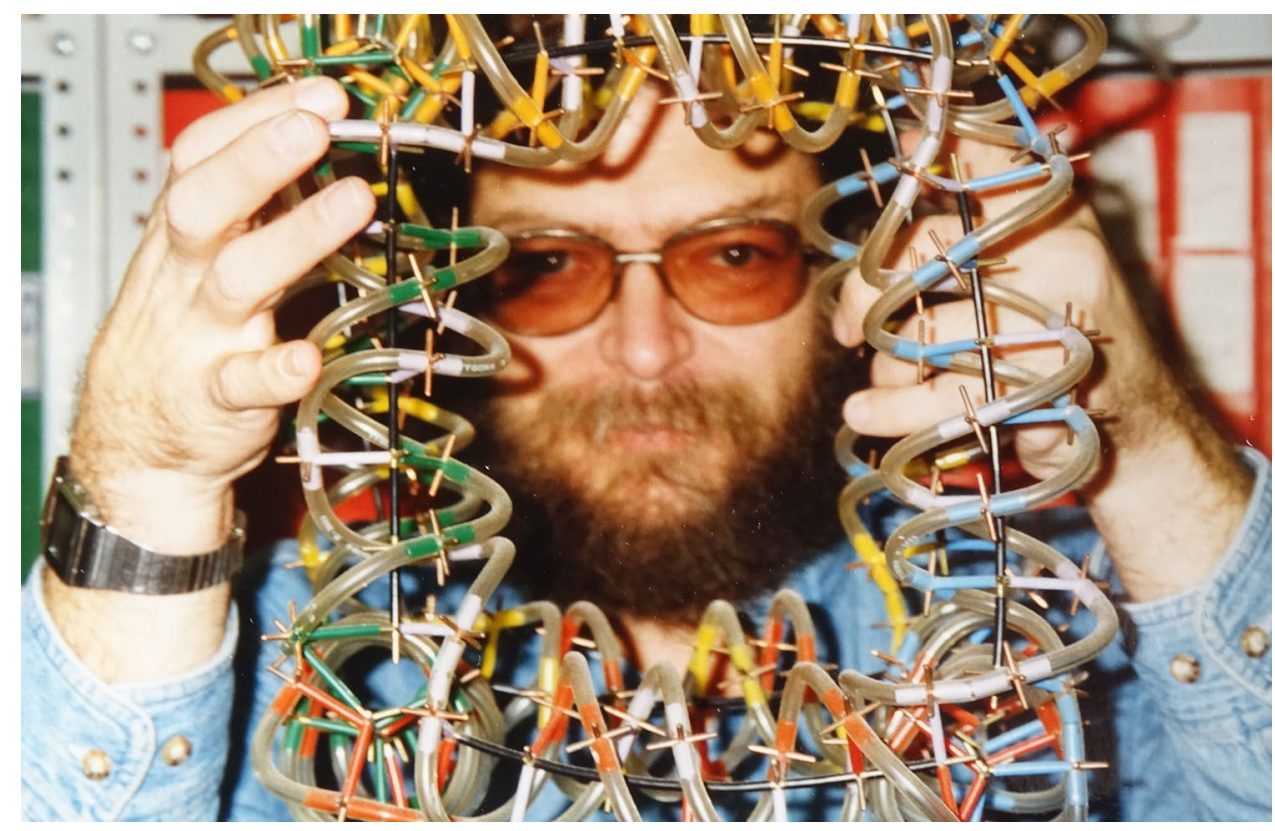

"Just because we can't do it doesn't mean we can't think about doing it." (Ned Seeman 1995)
Istvan Hargittai

stuceditor@gmail.com

Balazs Hargittai

bhargittai@francis.edu

1 Department of Inorganic and Analytical Chemistry, Budapest University of Technology and Economics, PO Box 91, Budapest 1521, Hungary

2 Department of Chemistry, Saint Francis University, 117 Evergreen Drive, Loretto, PA 15940, USA
Nadrian (Ned) C. Seeman (1945-2021, Figs. 1 and 2) was born in Chicago. His interest in science was ignited by a high school biology teacher and was also stimulated by the enhanced interest in science education in the USA in the wake of the first Soviet Sputnik. While being a medical undergraduate at the University of Chicago, he realized that research could also be a profession and decided to pursue such a career. He earned his PhD in biochemistry at the 
Fig. 2 Ned Seeman in his laboratory at New York University, 1995, photograph by the authors

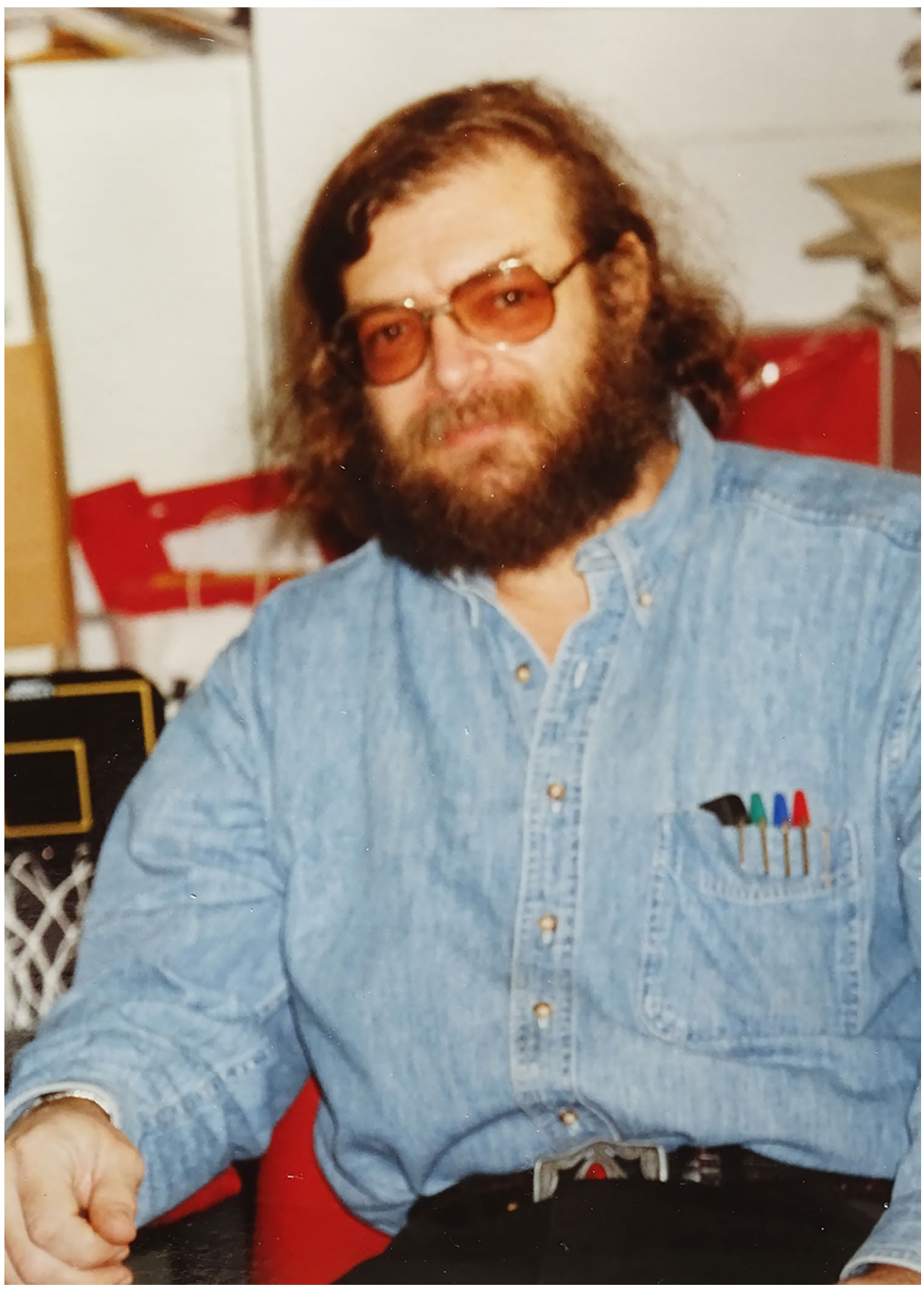

University of Chicago followed by postdoctoral work first at Columbia University and, then, with the legendary crystallographer, Alexander Rich, at the Massachusetts Institute of Technology. His studies with Rich cemented his interest in the structure of large biological molecules. In 1977, Seeman was appointed to the Biology Department of the State University of New York at Albany. There, while not especially successful in various projects, he stumbled upon the concept of the so-called Holliday junction, which caught his imagination. The Holliday junction was described by the molecular biologist Robin Holliday in 1964. It is a branched nucleic acid structure, which joins four double-stranded arms. Playing with its model led Seeman to develop his life motif, constructing three-dimensional DNA structures, and he became a nano-architect. From the early 1980s, he built the most diverse constructions of DNA; it has become his playground. By then, he had already become a member of the Faculty of the Department of Chemistry of New York University where he stayed to the end of his life.

Among his many research papers, he published a beautiful article, one of the first features in the fledgling magazine of the culture of chemistry, The Chemical Intelligencer [1]. 
He explained the basic concepts of nanoscience for a broad readership. He was a master of prose. The article could also be considered a statement of his research program. This article in this short-lived periodical is little known, so it is worthwhile to tell our readers a bit more about its contents. Seeman was keen to think of new, heretofore never seen or even imagined structures. Once he came to a structure that he fancied, he attempted to make it. For example, he was thinking about control of molecular structure similar to the control that craft workers exercise over their devices on a macroscopic scale. This is what Seeman and others have called nanotechnology. He pointed to the fuzziness of the boundaries between the macroscopic, microscopic, and the nanometer scales. Expressing it with sizes, the macroscopic scale is characteristic of objects of $10^{-7} \mathrm{~m}$ and larger, and the microscopic, of $10^{-9} \mathrm{~m}$ and smaller (the chemical bonds are typically in the $10^{-10}-\mathrm{m}$ range). Finally, the nanometer scale is in the range of $10^{-9}$ to $10^{-7} \mathrm{~m}$. In chemistry, there are means for bonding molecules, but not by "nails" or "cement" as fasteners as in macroscopic construction. Self-assembly in biological system comes closest in chemistry to macroscopic construction and Seeman started thinking about using DNA molecules for such purpose in 1980 soon after he had come across the concept of Holliday junction mentioned above.

He used DNA for the most diverse constructions and his office was full of intriguing models, which could be compared only to the storage room of models of the MRC Laboratory of Molecular Biology in Cambridge. His knowledge of crystallography along with his fertile imagination helped his designs in exploring the possibilities of DNA construction. In his 1995 article, mentioned above, he described in great detail the analogy between his structures and some of M.C. Escher's art, the Depth woodcut and the lithograph Cubic Space Division.

In all the fairy-tale-like world of exciting constructions, Seeman realized their important limitations as well. The constructions on a nanometer scale differed substantially from those on the chemical scale, which he called the angstrom scale-using a non-IS unit. The limitations on the chemical scale are set by the physical laws. Just as an example, carbon-carbon bonds have well-defined ranges of length outside of which it is impossible to count on their utilization. So, the constructions on the nanometer scale could not be considered to possess the properties ascribable to chemical systems. In contrast, those on the nanometer scale could be viewed as the smallest on the macroscopic scale. Thus, when classifying objects according to sizes, it is more than just size considerations that come into play. They are different in their nature. Having such caveats in mind does not subtract from the importance and broad applicability of the nanostructures pioneered by Seeman and others. On the contrary, it helps defining the areas of their applicability. A wide range of devices, nanomotors, and nanocomputers have been created or are anticipated to appear as fruits of nanotechnology. Such achievements and anticipations directed the 2016 Nobel Prize in Chemistry to three scientists "for the design and synthesis of molecular machines." Although Seeman was not among them, he received many other accolades and awards, some comparable to the Nobel in monetary aspect if not in fame.

Of the numerous recognitions, we single out those he was bestowed in the single year 2010 to indicate their riches and flavor. He had a John Simon Guggenheim Fellowship for 2010-2011. He was elected foreign member of the Norwegian Academy of Science and Letters and was awarded the Alexander Rich Medal from the Massachusetts Institute of Technology in the same year. And, to top it all, he was co-recipient of the Kavli Prize in Nanoscience in 2010, shared with another pioneer of the field, Donald Eigler of IBM Almaden Research Center in San Jose, CA. The joint motivation read: "for their development of unprecedented methods to control matter on the nanoscale." The monetary award of the Kavli Prize is one million US dollars in each of its three categories: astrophysics, nanoscience, and neuroscience. On the basis of the recommendations of independent committees, the Norwegian Academy of Science and Letters selects the laureates and the King of Norway hands over the prizes in a festive ceremony. The Kavli Prize has been awarded since 2008.

As far as we know, Seeman's last recognition was his election to membership of the American Academy of Arts and Sciences in 2017. One of his last publications appeared in 2020 in which he looked back at 40 years of DNA nanotechnology [2]. He ended the account with the following words: "My own laboratory is today engaged in using DNA nanotechnology in studies of self-replication and the organization of nanoelectronics. New 3D materials are an interesting route, and many laboratories are working in that direction. Every day I open a journal and I' $m$ surprised by another unit of progress in the nanoscale control of the structure of matter that DNA nanotechnology offers. I like being surprised that way." Sadly, Seeman will not surprise us with new constructions anymore, but all new surprises in the field will have something of his contributions in them. He will be missed by many and remembered by an ever growing scientific field.

\section{References}

1. Seeman NC (1995) Molecular craftwork with DNA. Chem Intell $1(2): 38-47$

2. Seeman NC (2020) Forty years of DNA nanotechnology. Nanoletters 20:1477-1478

Publisher's Note Springer Nature remains neutral with regard to jurisdictional claims in published maps and institutional affiliations. 